\title{
POTENSI PEMANFAATAN KAYU GELAM DAN KAYU SENGON DALAM DUNIA KONSTRUKSI BERDASARKAN UJI KUAT LENTUR
}

\author{
Basyaruddin $^{1}$, Alnovia Suryaningsih ${ }^{2}$, Jatmoko Awali $^{3}$ \\ ${ }^{1}$ Dosen, Asisten Ahli, Teknik Sipil, Institut Teknologi Kalimantan \\ ${ }^{2}$ Mahasiswa, Teknik Sipil, Teknik Sipil dan Perencanaan, Institut Teknologi Kalimantan \\ ${ }^{3}$ Dosen, Asisten Ahli, Teknik Material dan Metalurgi, Institut Teknologi Kalimantan \\ *Korespondensi: basyaruddin@lecturer.itk.ac.id
}

\begin{abstract}
In 2013, The Ministry of Forestry revealed that the need for wood as material for construction was always increasing. In order to find the innovations regarding timber structure, this study was conducted to discover the flexural strength of gelam and sengon based on SNI 03-3959-1995. Also, specimens which $50 \mathrm{~mm}$ in depth, $50 \mathrm{~mm}$ in height and $760 \mathrm{~mm}$ in length were tested using two point loading method based on ASTM D-198. This research showed that the average flexural strength of gelam is 100.13 Mpa which is greater than sengon (82.62 Mpa). Furthermore, as simple truss structure, simulation indicated that gelam and sengon are still capable in resisting moment generated from service load.
\end{abstract}

Keywords :flexural strength, gelam, sengon, truss structure

\section{PENDAHULUAN}

Kebutuhan akan kayu olahan sebagai bahan bangunan selalu meningkat. Menurut Jihannanda (2013) [1], di Indonesia, setiap tahun rata-rata tidak kurang dari 3 juta $\mathrm{m}^{3}$ kayu gergajian dihasilkan untuk memenuhi kebutuhan pembangunan perumahan, gedung dan lain sebagainya. Namun, kayu gergajian bermutu baik semakin sulit ditemui di pasaran karena semakin menipisnya produksi hasil hutan. Menurut Syafi'i (1998) dan Jihannanda (2013) [2], di masa mendatang diperkirakan potensi kayu dan luas hutan alam Indonesia semakin menyusut, sehingga pasokan bahan baku kayu harus diperoleh dari produksi hutan tanaman industri (HTI). Oleh karena itu, upaya untuk meningkatkan effisiensi penggunaan bahan baku kayu dapat dilakukan dengan pemanfaatan jenis-jenis kayu cepat tumbuh dan mutu rendah yang salah satunya adalah kayu gelam yang dapat dengan mudah ditemukan di pasaran. Selain kayu gelam, kayu sengon juga merupakan kayu sedang dibudidayakan oleh pemerintah Kalimantan Tengah. Namun, informasi terkait kekuatan yang dimiliki oleh kedua jenis kayu tersebut sangatlah minim sehingga peneliti dalam hal ini tertarik untuk mengkaji lebih lanjut terkait kekuatan kayu gelam dan sengon apabila diaplikasikan dalam suatu konstruksi bangunan.

\section{TINJAUAN PUSTAKA}

Kalimantan memiliki banyak jenis kayu yang dapat dijadikan sebagai bahan konstruksi bangunan, salah satunya kayu gelam. Kayu gelam (Melaleuca sp.) termasuk kelas kuat II dan kelas awet III (Kementerian Kehutanan, 2013) [3] yang tumbuh pada dataran rendah berawa, dijual dengan harga yang relatif murah dan mudah didapat. Umumnya kayu gelam yang memiliki diameter kecil dipakai sebagai steger pada konstruksi bangunan dengan dasar beton, sedangkan yang berdiameter besar biasa dipakai untuk cerucuk pada pekerjaan sungai dan jembatan (Supriyati dkk, 2014) [4].

Kayu yang mulai dikembangkan sebagai tanaman industri di Kalimantan Tengah bekerjasama dengan Borneo Institute sebuah organisasi dari Jerman adalah kayu sengon. Penanaman satu juta pohon sengon ini digunakan untuk industri karena masa panennya hanya sekitar 5 tahun serta banyak 
dicari oleh pasar (ralian, 2018) [5]. Kayu sengon, termasuk kayu kelas kuat IV sampai V dengan berat jenis rata-rata 0,33 serta kelas awet IV sampai V. Secara umum kayu sengon mempunyai nilai penyusutan yang rendah dan menurut Kasmudjo (2001) dalam Jihannanda (2013) [6] Kayu sengon umur 5 tahun dapat dipakai sebagai kayu struktur bangunan sederhana.

Balok kayu sengon dan kayu gelam menjadi pilihan dalam penelitian ini, mengingat kayu gelam banyak ditemukan di Pulau Kalimantan dan kayu sengon mulai banyak dikembangkan oleh masyarakat kelompok tani. Dengan penelitian ini, diharapkan dapat mengetahui sifat karakteristik dari kayu gelam dan kayu sengon serta mengetahui besar kuat lentur balok kayu gelam dan sengon.

Pada penelitian ini, dilakukan pengujian berupa sifat fisik dan mekanik pada kayu sengon dan gelam. Pengujian sifat fisik berupa kadar air, berat jenis, dan elastisitas, sedangkan pengujian sifat mekanik berupa kuat lentur. Manfaat dilakukannya penelitian ini adalah sebagai gambaran mengenai nilai kuat lentur balok kayu sengon dan gelam yang ada di Pulau Kalimantan.

\section{METODOLOGI PENELITIAN}

\subsection{Prosedur Penelitian Kadar Air Kayu}

Uji kadar air pada kayu berdasarkan standar uji NI-5 PKKI 1961 [7] dan ASTM D4442-92 [8] yang bertujuan untuk menentukan berat air terhadap kayu dengan cara membandingkan berat kayu ketika sebelum di oven dan sesudah di oven. Kadar air kayu dihitung berdasarkan persamaan (1).

$$
\omega=\frac{W_{1}-W_{2}}{W_{2}}
$$

Dimana :

$$
\begin{array}{ll}
\omega & =\text { Kadar Air }(\%) \\
W_{1} & =\text { Berat awal }(g r) \\
W_{2} & =\text { Berat kering oven }(g r)
\end{array}
$$

\subsection{Prosedur Penelitian Berat Jenis Kayu}

Uji berat jenis kayu yang mengacu pada NI-5 PKKI 1961 dan ASTM D2395-14 [9] adalah rasio massa kering oven dari suatu benda uji terhadap massa volume air yang sama pada volume benda uji pada kadar air tertentu. Persamaan (2) digunakan untuk mengetahui berat jenis kayu.

$$
S_{M}=\frac{K m_{M}}{V_{M}}
$$

Dimana:

$$
\begin{array}{ll}
S_{M} & =\text { Berat Jenis }\left(\mathrm{gr} / \mathrm{cm}^{3}\right) \\
K & =\text { Konstanta, } K=1 \\
m_{M} & =\text { Berat Kering Udara }(\mathrm{gr}) \\
V_{M} & =\text { Volume sampel, } p \text { x lxt }\left(\mathrm{cm}^{3}\right)
\end{array}
$$

\subsection{Prosedur Penelitian Kuat lentur Kayu}

Uji lentur pada kayu mengacu pada standar SNI 03-3959-1995 [10] dan ASTM D 143-94 (2000) [11] dengan tujuan mendapatkan nilai kuat lentur dan MOE pada kayu. Desain pengujian di lapangan ditampilkan pada Gambar 1 berikut.

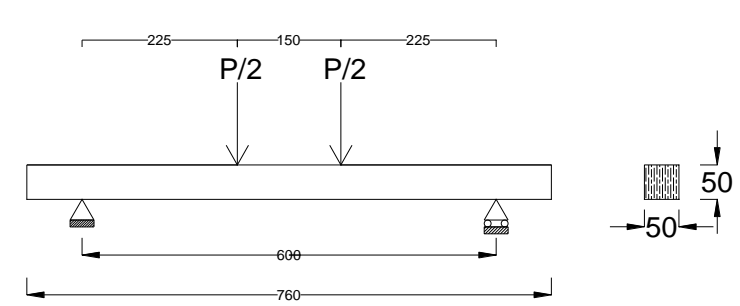

Gambar 1. Two Point Loading

Kuat lentur kondisi lapangan dapat diketahui dengan menggunakan persamaan (3) sebagai berikut.

$$
\text { olentur }=\frac{9}{8} \frac{P L}{b h^{2}}
$$

Dimana :

$$
\begin{array}{ll}
P & =\text { Beban Uji Maksimum }(N) \\
L & =\text { Jarak Tumpuan }(\mathrm{mm}) \\
B & =\text { Lebar Benda Uji }(\mathrm{mm}) \\
H & =\text { Tinggi Benda Uji }(\mathrm{mm}) \\
\text { olentur } & =\text { Kuat Lentur }(\mathrm{Mpa})
\end{array}
$$

Berdasarkan ASTM D-198 [12], nilai elastisitas dengan dua pembebanan kondisi lapangan dapat dihitung menggunakan persamaan (4) sebagai berikut.

$$
M O E=\frac{\Delta P a\left(3 L^{2}-4 a^{2}\right)}{4 \Delta y b h^{3}}
$$

Dimana :

$$
\begin{aligned}
M O E= & \text { Modulus of Elasticity }(\mathrm{Mpa}) \\
\Delta P \quad= & \text { Perubahan beban yang terjadi } \\
& \text { dibawah batas proporsi }(\mathrm{N}) \\
a \quad= & \text { jarak antara beban dengan tumpuan } \\
& \text { terdekat }(\mathrm{mm}) \\
L \quad= & \operatorname{Jarak} \text { sangga }(\mathrm{mm})
\end{aligned}
$$


$\Delta y \quad=$ Perubahan defleksi akibat beban $(\mathrm{mm})$

$B \quad=$ lebar contoh uji $(\mathrm{mm})$

$h \quad=$ tebal contoh uji $(\mathrm{mm})$

\section{HASIL DAN PEMBAHSAN}

\subsection{Sifat Fisik}

\subsubsection{Kadar Air}

Kadar air di dalam kayu ditentukan oleh air bebas dan air terikat (Haygreen dan Bowyer 2003) [13]. Nilai kadar air kayu juga bergantung pada kelembaban udara disekitarnya. Berikut ini Tabel 1 yang menampilkan hasil pengujian kadar air pada kayu sengon dan kayu gelam.

Tabel 1. Kadar Air Kayu Sengon dan Gelam

\begin{tabular}{cccc}
\hline $\begin{array}{c}\text { Jenis } \\
\text { Kayu }\end{array}$ & $\begin{array}{c}\text { No } \\
\text { Kode }\end{array}$ & $\begin{array}{c}\text { Kadar } \\
\text { Air } \\
(\boldsymbol{\%})\end{array}$ & $\begin{array}{c}\text { Kadar Air } \\
\text { Rata-Rata } \\
(\boldsymbol{\%})\end{array}$ \\
\hline \multirow{5}{*}{ Sengon } & S1 & 19.72 & \\
& S2 & 20.60 & \\
& S3 & 19.95 & 20.07 \\
& S4 & 18.93 & \\
& S5 & 20.83 & \\
Gelam & S6 & 20.39 & \\
& G1 & 42.71 & \\
& G2 & 28.20 & \\
& G3 & 29.24 & 34.66 \\
& G4 & 31.40 & \\
& G5 & 37.35 & \\
\hline
\end{tabular}

Berdasarkan Tabel 1 di atas, diketahui kadar air rata-rata dari kayu gelam adalah $34.66 \%$ sedangkan kayu sengon 20.07\%, menyatakan bahwa menurut PKKI 1961 kayu gelam dan sengon yang digunakan dalam penelitian memiliki kadar air antara $20-400 \%$ yang merupakan kayu basah.

\subsubsection{Berat Jenis}

Berat jenis merupakan sifat fisik kayu yang banyak digunakan untuk menduga sifat-sifat kayu lainnya. Berat jenis kayu ditentukan oleh tebal dinding sel dan ukuran rongga sel. Bahan kimia yang terdapat pada dinding sel juga akan mempengaruhi nilai berat jenis kayu (Haygreen dan Bowyer, 2003) [13]. Tabel 2 menunjukkan berat jenis untuk masing-masing kayu sengon dan kayu gelam.
Tabel 2. Berat Jenis Kayu Sengon dan Gelam

\begin{tabular}{|c|c|c|c|}
\hline $\begin{array}{l}\text { Jenis } \\
\text { Kayu }\end{array}$ & $\begin{array}{c}\text { No } \\
\text { Kode }\end{array}$ & $\begin{array}{c}\text { Berat } \\
\text { Jenis } \\
\left(\mathrm{gr} / \mathrm{cm}^{\mathbf{3}}\right) \\
\end{array}$ & $\begin{array}{c}\text { Berat Jenis } \\
\text { Rata-Rata } \\
\left(\mathrm{gr} / \mathrm{cm}^{3}\right)\end{array}$ \\
\hline \multirow{6}{*}{ Sengon } & S1 & 0.33 & \multirow{6}{*}{0.36} \\
\hline & $\mathrm{S} 2$ & 0.34 & \\
\hline & S3 & 0.39 & \\
\hline & S4 & 0.35 & \\
\hline & S5 & 0.34 & \\
\hline & S6 & 0.41 & \\
\hline \multirow{6}{*}{ Gelam } & G1 & 0.95 & \multirow{6}{*}{0.91} \\
\hline & G2 & 0.88 & \\
\hline & G3 & 0.87 & \\
\hline & G4 & 0.91 & \\
\hline & G5 & 0.91 & \\
\hline & G6 & 0.92 & \\
\hline
\end{tabular}

Berdasarkan Tabel 2 di atas, diketahui berat jenis rata-rata dari kayu gelam adalah $0.91 \mathrm{gr} / \mathrm{cm}^{3}$ yang berdasarkan PKKI 1961, kayu gelam termasuk kelas kuat I karena memiliki berat jenis $>0.9$ sedangkan kayu Sengon memiliki berat jenis $0.36 \mathrm{gr} / \mathrm{cm}^{3}$ yang merupakan jenis kayu kelas kuat IV karena memiliki berat jenis antara 0.3-0.4

\subsubsection{Elastisitas}

Elastisitas adalah kemampuan benda untuk kembali ke bentuk aslinya setelah mengalami deformasi dan dalam penelitian ini, persamaan (4) digunakan untuk mengetahui elastisitas. Masing-masing elastisitas gelam dan sengon dapat dilihat pada Tabel 3.

Tabel 3. Elastisitas Kayu Sengon dan Gelam

\begin{tabular}{cccc}
\hline $\begin{array}{c}\text { Jenis } \\
\text { Kayu }\end{array}$ & No Kode & E (Mpa) & $\begin{array}{c}\text { E rata-rata } \\
\text { (Mpa) }\end{array}$ \\
\hline \multirow{6}{*}{ Sengon } & S1 & 18912.59 & \\
& S2 & 8545.12 & \\
& S3 & 6989.90 & 10812.65 \\
& S4 & 6452.54 & \\
& S5 & 5213.36 & \\
\hline \multirow{6}{*}{ Gelam } & G1 & 7904.35 & \\
& G2 & 11675.74 & \\
& G3 & 27304.49 & 13992.54 \\
& G4 & 11140.91 & \\
& G5 & 11937.20 & \\
\hline
\end{tabular}

Dari hasil penelitian elastisitas pada kayu sengon dan gelam di atas diperoleh nilai elastisitas rata-rata pada kayu gelam lebih besar dibanding kayu sengon dengan nilai elastisitas kayu gelam sebesar sebesar 13992.54 Mpa. 


\subsection{Sifat Mekanik}

\subsubsection{Kuat Lentur}

Kuat lentur adalah nilai tegangan tarik yang dihasilkan dari momen lentur dibagi dengan momen penahan penampang balok uji dan persamaan yang digunakan untuk mengetahui kuat lentur kondisi lapangan adalah persamaan (3). Nilai kuat lentur kayu gelam dan sengon dapat dilihat pada Tabel 4.

Tabel 4. Kuat Lentur Kayu Sengon dan Gelam

\begin{tabular}{cccc}
\hline $\begin{array}{c}\text { Jenis } \\
\text { Kayu }\end{array}$ & $\begin{array}{c}\text { No } \\
\text { Kode }\end{array}$ & $\begin{array}{c}\text { Kuat } \\
\text { lentur } \\
\text { (Mpa) }\end{array}$ & $\begin{array}{c}\text { Kuat Lentur } \\
\text { Rata-Rata } \\
\text { (Mpa) }\end{array}$ \\
\hline \multirow{5}{*}{ Sengon } & S1 & 114.75 & \\
& S2 & 83.71 & \\
& S3 & 84.34 & 82.62 \\
& S4 & 58.57 & \\
& S5 & 71.72 & \\
\hline \multirow{5}{*}{ Gelam } & G1 & 87.85 & \\
& G2 & 93.71 & \\
& G3 & 109.69 & 100.13 \\
& G4 & 103.27 & \\
& G5 & 106.14 & \\
\hline
\end{tabular}

Tabel 4 di atas menunjukkan bahwa kuat lentur gelam secara rata-rata memiliki nilai yang lebih besar dibandingkan dengan kuat lentur sengon dimana masing-masing nilai kuat lentur adalah 100.13 Mpa dan 82.62 Mpa.

\subsubsection{Perbandingan Kuat Lentur dengan} Lendutan

Perbandingan lendutan vs kayu gelam dan sengon dapat dilihat pada Gambar 2.

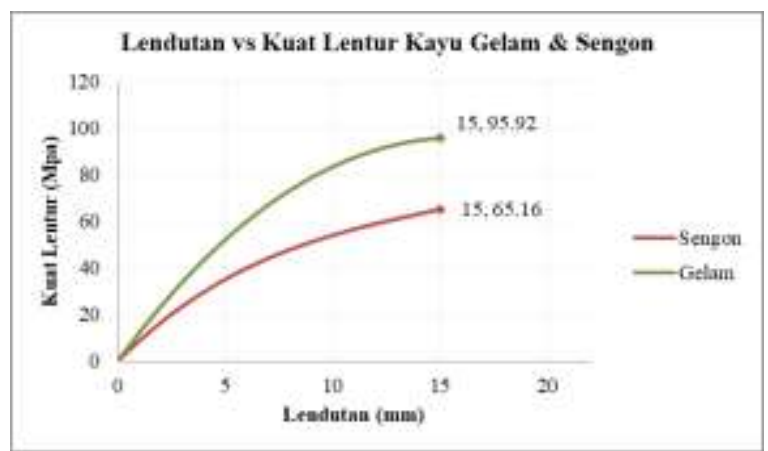

Gambar 2. Grafik Kuat Lentur Gabungan Rata-Rata Kayu Sengon dan Kayu Gelam

Berdasarkan Gambar 2, dapat dilihat bahwa untuk mencapai nilai lendutan yang sama $(15 \mathrm{~mm})$ kayu gelam membutuhkan nilai kuat lentur yang lebih besar dari pada sengon.
Hal ini menunjukkan bahwa gelam dapat menahan beban yang lebih besar dari pada sengon.

\subsection{Aplikasi Pengujian Kuat Lentur Kayu dengan Analisa SAP}

Pada hasil penelitian yang telah diperoleh, dilakukan analisa terhadap software SAP dengan mengkonsruksikan ke dalam rumah sederhana. Material kayu digunakan untuk pekerjaan bagian atap berupa kuda-kuda, gording, dan ringbalk. Dimensi yang digunakan sebagai berikut:

$\begin{array}{ll}\text { Kuda-kuda } & =8 \mathrm{~cm} \times 12 \mathrm{~cm} \\ \text { Gording } & =8 \mathrm{~cm} \times 12 \mathrm{~cm} \\ \text { Ringbalk } & =15 \mathrm{~cm} \times 20 \mathrm{~cm}\end{array}$

\subsubsection{Pembebanan pada SAP}

Beban yang digunakan pada perencanaan menggunakaan aplikasi SAP sebagai berikut.

1. Beban Mati, berdasarkan PPIUG tahun 1983 [14] digunakan penutup genting yang menggunakan reng dan usuk/kaso dengan beban sebesar $50 \mathrm{~kg} / \mathrm{m}^{2}$ dan pada kuda-kuda terdapat pasangan bata (setengah batu) dengan beban sebesar 250 $\mathrm{kg} / \mathrm{m}^{2}$.

2. Beban Hidup di Atap, berdasarkan PPIUG tahun 1983 yang dapat dibebani oleh orang harus diambil sebesar $100 \mathrm{~kg} / \mathrm{m}^{2}$.

3. Beban Hujan, berdasarkan PPIUG tahun 1983 diambil nilai sebesar $20 \mathrm{~kg} / \mathrm{m}^{2}$.

4. Beban Angin, berdasar SNI 1727:2013 tentang "Beban Minimum untuk Perencanaan Bangunan Gedung dan Struktur Lain" memiliki nilai sebesar 38 $\mathrm{kg} / \mathrm{m}^{2}$.

\subsubsection{Pengecekan Kapasitas}

Tegangan kuat lentur untuk masing-masing elemen (Kuda-kuda, Gording dan Ring Balk) akibat setiap kombinasi pembebanan dapat dilihat pada Tabel 5.

Tabel 5 menunjukkan bahwa tegangan lentur yang terjadi untuk masing-masing elemen sangat bervariasi dan tegangan lentur yang paling besar terjadi di kuda-kuda akibat kombinasi pembebanan $1.2 \mathrm{D}+1.6$ HidupAtap dengan nilai $23.08 \mathrm{Mpa}$. Selanjutnya tegangan lentur yang terjadi dibandingkan dengan kapasitas tegangan lentur (kuat lentur) gelam dan sengon yang diperoleh melalui pengujian yang telah dijelaskan sebelumnya. Hasil perbandingan tegangan lentur yang terjadi di kuda-kuda dengan kapasitas tegangan lentur 
gelam dan sengon dapat dilihat pada Tabel 6.

Tabel 5. Rekapitulasi Kuat Lentur pada SAP

\begin{tabular}{|c|c|c|c|c|}
\hline \multirow{2}{*}{ No } & \multirow{2}{*}{ Kombinasi Beban } & Gording & Kuda-Kuda & Ringbalk \\
\hline & & Teg. Lentur (Mpa) & Teg. Lentur (Mpa) & Teg. Lentur (Mpa) \\
\hline 1 & 1.4D & 6.62 & 11.90 & 8.30 \\
\hline 2 & $1.2 \mathrm{D}+1.6 \mathrm{~L}+0.5$ HidupAtap & 7.97 & 14.23 & 10.57 \\
\hline 3 & $1.2 \mathrm{D}+1.6 \mathrm{~L}+0.5 \mathrm{Hujan}$ & 6.47 & 11.81 & 8.18 \\
\hline 4 & 1.2D+1.6Hidup Atap & 13.00 & 23.08 & 18.16 \\
\hline 5 & $1.2 \mathrm{D}+1.6 \mathrm{Hujan}$ & 8.33 & 15.36 & 10.52 \\
\hline 6 & $1.2 \mathrm{D}+1 \mathrm{~L}$ & 5.50 & 6.55 & 7.12 \\
\hline 7 & 1.2D+0.8Angin & 8.03 & 11.61 & 8.09 \\
\hline 8 & $1.2 \mathrm{D}+1.6 \mathrm{Angin}+1 \mathrm{~L}+0.5 \mathrm{Hidup}$ & 12.63 & 20.33 & 13.95 \\
\hline 9 & $1.2 \mathrm{D}+1.6 \mathrm{Angin}+1 \mathrm{~L}+0.5 \mathrm{Hujan}$ & 11.46 & 18.00 & 12.73 \\
\hline 10 & $0.9 \mathrm{D}+1.6$ Angin & 9.28 & 15.52 & 11.20 \\
\hline 11 & $0.9 \mathrm{D}$ & 4.26 & 7.65 & 5.34 \\
\hline
\end{tabular}

Tabel 6. Perbandingan Nilai Kuat Lentur Kuda-Kuda dengan Kuat Lentur Penelitian

\begin{tabular}{|c|c|c|c|c|}
\hline \multirow{2}{*}{ No } & \multirow{2}{*}{ Kombinasi Beban } & Kuda-Kuda & Sengon & Gelam \\
\hline & & Teg. Lentur (Mpa) & $\sigma=70.23 \mathrm{Mpa}$ & $\sigma=85.11 \mathrm{Mpa}$ \\
\hline 1 & $1.4 \mathrm{D}$ & 11.90 & Oke & Oke \\
\hline & $1.2 \mathrm{D}+1.6 \mathrm{~L}+0.5$ HidupAtap & 14.23 & Oke & Oke \\
\hline 3 & $1.2 \mathrm{D}+1.6 \mathrm{~L}+0.5 \mathrm{Hujan}$ & 11.81 & Oke & Oke \\
\hline 4 & 1.2D+1.6Hidup Atap & 23.08 & Oke & Oke \\
\hline 5 & $1.2 \mathrm{D}+1.6 \mathrm{Hujan}$ & 15.36 & Oke & Oke \\
\hline 6 & $1.2 \mathrm{D}+1 \mathrm{~L}$ & 6.55 & Oke & Oke \\
\hline 7 & $1.2 \mathrm{D}+0.8$ Angin & 11.61 & Oke & Oke \\
\hline 8 & $1.2 \mathrm{D}+1.6$ Angin $+1 \mathrm{~L}+0.5$ HidupAtap & 20.33 & Oke & Oke \\
\hline & $1.2 \mathrm{D}+1.6 \mathrm{Angin}+1 \mathrm{~L}+0.5 \mathrm{Hujan}$ & 18.00 & Oke & Oke \\
\hline & $0.9 \mathrm{D}+1.6$ Angin & 15.52 & Oke & Oke \\
\hline 11 & $0.9 \mathrm{D}$ & 7.65 & Oke & Oke \\
\hline
\end{tabular}

Tabel 6 memperlihatkan bahwa kapasitas tegangan lentur yang dimiliki oleh gelam dan sengon masih lebih besar dibandingkan dengan tegangan lentur yang harus ditahan akibat kombinasi pembebanan yang telah direncanakan. Hal ini mengindikasikan bahwa kayu gelam dan sengon berpotensi untuk dimanfaatkan dalam konstruksi sederhana seperti rangka atap rumah sederhana.

\section{PENUTUP}

\subsection{Kesimpulan}

Dari hasil penelitian yang telah dilakukan, diperoleh beberapa kesimpulan sebagai berikut.

1. Kadar air rata-rata dari kayu sengon sebesar $20.07 \%$ sedangkan kayu gelam sebesar $34.66 \%$ yang merupakan kayu basah.

2. Berat jenis rata-rata kayu sengon sebesar $0.36 \mathrm{gr} / \mathrm{cm}^{3}$ yang termasuk kelas kuat IV dan kayu gelam sebesar $0.91 \mathrm{gr} / \mathrm{cm}^{3}$ yang termasuk kelas kuat I.

3. Nilai Elastisitas rata-rata dari kayu gelam lebih besar dibanding kayu sengon dengan nilai sebesar $13992.54 \mathrm{Mpa}$.

4. Nilai kuat lentur rata-rata kayu gelam lebih besar dibanding kayu sengon dengan nilai sebesar 100.13 Mpa.
5. Nilai kuat lentur dari analisa SAP dengan pembebanan maksimum pada kombinasi 1.2D + 1.6 Hidup Atap dengan nilai kuat lentur pada masing-masing elemen untuk gording sebesar $13.00 \mathrm{Mpa}$, kuda-kuda sebesar $23.08 \mathrm{Mpa}$, dan untuk ringbalk sebesar 18.16 Mpa yang masih memenuhi atau kurang dari nilai kuat lentur hasil pengujian laboratorium.

\section{DAFTAR PUSTAKA}

[1] Anonim. 1971. Peraturan Konstruksi Kayu Indonesia PKKI 1961. Penerbit Departemen Pekerjaan Umum, Direktorat Jenderal Cipta Karya, Direktorat Penyelidikan Masalah Bangunan, Bandung.

[2] Anonim. 1983. Peraturan Pembebanan Indonesia untuk Gedung. Yayasan Lembaga Penyelidikan Masalah Bangunan : Bandung.

[3] ASTM D 4442 - 92 (Reapproved 2003). Standard Test Methods for Direct Moisture Content Measurement of Wood and Wood-Base Materials.

[4] ASTM D 2395 - 14. 2015. Standard Test Methods for Density and Specific Gravity (Relative Density) of Wood and Wood-Based Materials.

[5] ASTM D 143 - 94 (Reapproved 2000). Standard Test Methods for Small Clear Specimens of Timber.

[6] ASTM D 198 - 15. 2016. Standard Test Methods of Static Tests of Lumber in Structural Sizes.

[7] Haygreen, JG \& J.L Bowyer. 1989. Hasil Hutan dan Ilmu Кауи - Suatu Pengantar. (Terjemahan Dr.Sutjipto A.Hadikusumo, Penyunting Prof. Dr. Ir.Soenardi Prawirohatmodjo). Gadjah Mada University Press : Yogyakarta.

[8] Jihannanda, Pramudito. 2013. Studi Kuat Lentur Balok Laminasi Кауи Gelam Dengan Kayu Kelapa di Daerah Gunung Pati Semarang. Tugas Akhir Fakultas Teknik Universitas Negeri Semarang.

[9] Kasmudjo. 2001. Pengantar Teknologi Hasil Hutan Bagian V Papan Tiruan Lain. Yayasan Pembina, Fakultas Kehutanan UGM. Yogyakarta.

[10] Kementerian Kehutanan. 2013. Atlas Kayu IV. Badan Penelitian dan Pengembangan Kehutanan. Pusat Penelitian dan Pengembangan Keteknikan Kehutanan dan Pengelolaan Hasil Hutan. Bogor.

[11] Ralian. 2018. Duduk Bersama Wujudkan Hasil Pohon Sengon Berkualitas. borneoinstitute.org

[12] SNI 03-3959-1995. Metode Pengujian Kuat 
Lentur Kayu Di Laboratorium.

[13] Supriyati, dkk. 2015. Kearifan Lokal Penggunaan Kayu Gelam dalam Tanah Rawa Gambut di Kalimantan Tengah. Jurnal Manusia dan Lingkungan Vol 22 (No 1): 94-99.
[14] Syafi'i, W. 1998. Pentingnya Penelitian Sifat-sifat Dasar Кауи Dalam Rangka Peningkatan Efisiensi Pemanfaatan Sumber Daya Hutan. Seminar Nasional I, Masyarakat Peneliti Kayu Indonesia (MAPEKI). Fakultas Kehutanan, IPB, Bogor. 